\title{
El discurso público mapuche: el caso del discurso estudiantil universitario*
}

The Mapuche Public Discourse: the case of university students' discourse

\author{
Hugo Carrasco Muñoz ${ }^{1}$, Sonia Betancour Sánchez ${ }^{2}$ \\ ${ }^{1}$ Universidad de la Frontera, Departamento Lenguas, Literatura y Comunicación, \\ Casilla 54-D, Temuco, Chile. e-mail: hcarrasc@ufro.cl / \\ ${ }^{2}$ Universidad de la Frontera, Departamento de Lenguas, Literatura y Comunicación, \\ Casilla 54-D, Temuco, Chile. e-mail: soniabet@ufro.cl. \\ Estudiante de Doctorado en Ciencias Humanas UACh
}

\begin{abstract}
El discurso público mapuche estudiado hasta ahora era el producido por dirigentes o representantes de organizaciones y otras instancias del pueblo mapuche. Aquí se describe un nuevo tipo de dpm, el producido por estudiantes universitarios, el cual demuestra la existencia de un tipo de discurso previsto teóricamente junto a otros de los cuales no se habían recogido evidencias empíricas. Entre los diversos problemas teóricos que se generan en el presente trabajo se enfrenta sólo uno de ellos: en la instancia comunicativa de este tipo discursivo se observa que el emisor/destinador mapuche se dirige a un receptor/destinatario también mapuche, rasgo discrepante con la norma del dpm según la cual el receptor/destinatario es la sociedad global chilena, lo que también pareciera dar al dpm-eu una fuerte orientación intracultural y no intercultural transformando su sentido básico.
\end{abstract}

Palabras clave: discurso público mapuche estudiantil universitario, intraculturalidad, interculturalidad, emisor/destinador, receptor/destinatario.

The Mapuche public discourse studied up to now has been the one produced by leaders or representatives of organizations and events of the Mapuche people. A new type of Mapuche public discourse (mpd) is described in this work: the one produced by university students which shows the existence of a kind of discourse theoretically foreseen and close to the other ones of which no empirical evidence had been collected. Of the many theoretical problems derived from this work only one of them is studied: it has been observed that in the communicative event in this kind of discourse the Mapuche sender addresses another Mapuche as a receiver, seen as a conflicting feature with the norm of the Mapuche public discourse in which the receiver is the global Chilean society what seems to give the mpd a strong intracultural and non-intercultural.

Key words: university student mapuche public discourse, intra-cultural, intercultural, emitter-sender, receiver.

\begin{abstract}
* El presente trabajo forma parte del Proyecto FONDECYT 1060359, del cual el autor principal es Investigador Responsable; coinvestigadores, las académicas del Depto. de Lenguas, Literatura y Comunicación de la Universidad de La Frontera Verónica Contreras y Mabel García, y colaboradores estudiantes de pregrado y de postgrado. La segunda autora es académica de la Ufro y estudiante del Doctorado en Ciencias Humanas Mención Discurso y Cultura de la Universidad Austral de Chile.
\end{abstract}

\section{INTRODUCCIÓN}

El discurso público mapuche, sobre el cual se empezó a investigar y escribir en forma sistemática en 1996, se ha constituido en un objeto de estudio significativo por las proyecciones políticas, socioculturales, mediales, educativas e interculturales que ha alcanzado en los últimos años su objetomateria en el contexto del pueblo mapuche y del país, y desde un punto de vista teórico por las investigaciones formales y publicaciones que se han desarrollado en torno a él ${ }^{1}$. No obstante, y como es normal en un ámbito que todavía no se ha desarrollado plenamente y sobre el cual aún falta mucho por discutir, corregir, incorporar y avanzar, nuestros nuevos trabajos, observaciones y lecturas nos exigen reconsiderar algunos aspectos de la teoría avanzada.

Como es conveniente recordar, en la primera publicación formal sobre el discurso público mapuche, por comodidad de aquí en adelante dpm, se definió el mismo a partir del fenómeno empírico que lo identifica como un tipo de discurso conformado por varios otros tipos menores de discurso creados por dirigentes y representantes mapuches con la clara finalidad de incidir con sus planteamientos

\footnotetext{
${ }^{1}$ Al respecto agradezco la consideración sobre el particular, que nos honra, de los profesores Gèrard Imbert, Miquel Rodrigo Alsina, José Luis Piñuel y, últimamente, Lorenzo Vilches.
} 
reivindicativos ante la sociedad global, lo que posteriormente fue precisado entendiéndolo como un "complejo textual heterogéneo"2. De este modo, a medida que se recogían materiales y se reflexionaba teóricamente sobre ellos, se fue avanzando en: a) el estatuto epistemológico del dpm, propuesto entre otros rasgos como polidiscurso del tipo complejo discursivo/textual, como se ha observado en los 3 o 4 tipos de discurso que lo componen (discurso para la prensa, discurso político, discurso académico y carta, conformados a su vez por declaraciones públicas, comunicados, manifiestos, propuestas, convocatorias, folletos y revistas, conclusiones de reuniones y congresos, cartas de diverso tipo ${ }^{3}$; b) en la formulación de los rasgos transversales comunes a estos tipos discursivos (1) un discurso de orden público, especificado por rasgos del tipo de discurso producido para la prensa, los otros medios e Internet, además de otros del discurso político y 'académico' con menor grado de incidencia, y de la carta; (2) intercultural, híbrido, apelativo, reforzador de identidad, funcionalmente reivindicativo) ${ }^{4}$, (3) y, últimamente, en la situación disciplinaria que le corresponde en cuanto forma de comunicación intercultural mediatizada 5 .

En consecuencia con lo anterior, se han propuesto varios rasgos que definen el dpm semánticamente en forma "transversal": intercultural, híbrido y heterogéneo, en cuanto tipo de discurso; orientado a la resistencia, mantención y reforzamiento de la identidad propia, aunque ha incorporado tipos de discurso, usos y contextos de la cultura mayoritaria de la sociedad nacional; de eficiencia funcional relativa, ya que el intercambio de discursos en la esfera pública se emplea como medio para alcanzar reivindicaciones y conquistas personales, culturales y socioeconómicas demandadas mediante los discursos, y al mismo tiempo como medio de expresión simbólica de identidad, estrategia elusiva y no persuasiva en la cual el dpm adopta una función representativa o declarativa, complemento o acompañante de otros tipos de acción con propósitos empíricamente efectivos (cfr. Carrasco 2001a: 5-6).

En este contexto, una investigación todavía reciente ${ }^{6}$, al observar y describir la existencia de un nuevo tipo de discurso público mapuche, el producido por estudiantes universitarios, se genera primero un interés de orden práctico al demostrar la existencia de un tipo de discurso previsto teóricamente junto a otros, pero del cual no se habían recogido evidencias empíricas ni estudiado, y de inmediato varios problemas teóricos, entre los cuales en el presente trabajo nos interesa enfrentar sólo uno de ellos: uno de los rasgos definitorios del dpm es el carácter intercultural, fundado en la existencia de una situación comunicativa en la cual la instancia destinador, constituida empíricamente por dirigentes o representantes mapuches que se dirigen de manera explícita a una instancia destinataria encarnada en representantes del Estado chileno, otras autoridades de orden variado de la sociedad mayoritaria y la opinión pública. Desde una lectura sociosemiótica se ha considerado que la significación profunda de este sistema corresponde claramente al conflicto intercultural propio de la situación del país, y en general de Latinoamérica, en donde los pueblos indígenas enfrentan una vez más a las sociedades criollas que los han sojuzgado y oprimido a través de sus Estados manifestados en los Gobiernos que los rigen ${ }^{7}$.

\footnotetext{
${ }^{2}$ Iván Carrasco (1979) ante la noción simple de 'texto' empleada en ese momento prefiere la más compleja de 'complejo textual heterogéneo', entendiéndolo en forma cercana a la teoría del texto de Schmidt (Teoría del Texto. Madrid, 1977) como un conjunto sistemático de tipos discursivos en los que predomina uno de ellos (cuerpo del texto o discurso base) y lo complementan otros presentes también en él (discursos complementarios). El carácter de 'heterogéneo' de este 'complejo textual' se entiende en el sentido de que los potenciales tipos discursivos pueden ser de carácter variado y diverso entre sí. El autor ejemplifica, entre otros casos, con poemas de Gabriela Mistral, en los cuales el discurso básico es de orden lírico y los discursos complementarios son del tipo títulos, epígrafes y notas. Con relación al dpm, nosotros hemos aprovechado esta teoría en su extensión al conjunto de tipos de discurso interrelacionados que conforman conceptualmente el discurso público mapuche y cuyas variadas vinculaciones se observan en los textos concretos del mismo.

${ }^{3}$ De acuerdo a esto, tendríamos 3 categorías amplias que se pueden considerar complejos discursivos 1) discurso para la prensa (declaración pública, comunicado); 2) discurso político (manifiesto, convocatoria, propuesta); 3) discurso 'académico' (revistas, conclusiones de congresos y similares). A estos grupos debe agregarse un cuarto: 4) la carta (carta abierta cercana al discurso para la prensa, y carta cerrada, difícil de considerar discurso público). Desde otro punto de vista se ha incorporado también la "carta mapuche".

${ }^{4}$ Dada la compleja estructuración del dpm, conformado por múltiples discursos dispares, sus rasgos generales o comunes a los discursos componentes son también variados, diversos y heterogéneos.

${ }^{5}$ El único trabajo al respecto es el de Hugo Carrasco: Estudios Filológicos № 37. 2002:185-197.

${ }^{6}$ Sonia Betancour: El discurso público mapuche estudiantil universitario. Tesis de Grado Magíster en Ciencias de la Comunicación, 2006. Dpto. Lenguas, Literatura y Comunicación, Universidad de La Frontera. Profesor Patrocinante Hugo Carrasco.

${ }^{7}$ Un aspecto de gran interés a considerar en otro momento es el hecho de que en coherencia con las actuales características de la sociedad y la cultura, los mapuches generan un tipo de discurso para enfrentar esta situación que incorpora precisamente el énfasis informativo y comunicacional de la sociedad globalizada desde su propio énfasis en un discurso público difundible por los medios.
} 
El discurso público de los estudiantes universitarios cumple con la mayoría de estas características. No obstante, hay un rasgo en que parece discrepar: los textos de discurso público, si bien en su mayoría están dirigidos formalmente a los miembros de la sociedad global o los chilenos winka, desde su contenido, argumentación y motivaciones se dirige a los miembros del pueblo indígena, los mapuches, por lo que pareciera tener una fuerte orientación intracultural y no intercultural. Si esto es así, conllevaría la modificación de la instancia comunicativa (destinador/destinatario) del discurso y traería como consecuencia la transformación o modificación de muchos de sus sentidos. Más en particular, esto rompería una de las características consideradas básicas del dpm, su carácter intercultural, generado justamente en medio y como parte del conflicto con los otros, con la sociedad mayoritaria distinta y dominante y culturalmente opuesta a la mapuche.

De este modo se abren numerosas interrogantes, algunas de fuerte incidencia empírica, pero como la experiencia ha enseñado que la más práctica y eficiente de las soluciones pasa por una buena explicación teórica, sistemática, coherente y demostrable es necesario ante todo explicarnos la interrogante de partida: el discurso público de los estudiantes universitarios mapuches ¿es o no es un discurso público, o en qué sentido es discurso público? Pese a contar con una instancia destinataria conformada por sujetos de la otra sociedad y cultura, este discurso público creado por los dirigentes y representantes comunitarios, ¿forma parte del mismo sistema del dpm? ¿O el hecho de que su instancia destinador está formada por estudiantes universitarios lo excluye de este sistema, o lo incluye en forma diferenciada? O, de darse esta última posibilidad, ¿esto significa que es el sistema mismo del dpm el que debe reformularse?

Para explicarnos este problema, se lo ha delimitado mediante objetivos específicos:

1) Evaluar la coherencia de la noción de dpm manejada hasta ahora, en particular su carácter de complejo textual heterogéneo que implica la existencia de variados tipos discursivos integrados en él;

2) Establecer los rasgos de la instancia comunicativa del discurso público de estudiantes universitarios mapuches desde el modo en que se relaciona con la sociedad mayoritaria y con el pueblo mapuche;

3) Definir la incidencia del grado intracultural o intercultural de la instancia destinador/destinatario del discurso de estudiantes universitarios en su inclusión o exclusión del discurso público mapuche.

En un tipo de reflexión teórica y en gran parte metateórica como ésta, el marco referencial que se ha elaborado sobre el discurso público mapuche, propuesta por nosotros mismos en el marco de la sociosemiótica, los estudios interculturales y la teoría de la comunicación, en particular la noción de complejo discursivo o textual que exige revisar la estructura textual en términos de los aspectos vinculados con las instancias del destinador y del destinatario y con el rasgo que incluye la oposición intraculturalidad/interculturalidad.

En este contexto, la hipótesis de trabajo que nos orienta supone que el dpm estudiantil universitario, si bien difiere del dpm en general por los rasgos que muestra en su instancia comunicativa y que a diferencia de él lo llevan a enfatizar el carácter intracultural del discurso, coincide con aquél en su funcionalidad hibridadora identitaria.

En concordancia con esto, la metodología principal tiene que ver con la revisión bibliográfica pertinente y actualizada y con la coherencia crítica y autocrítica que se alcance. Por lo mismo, se han delimitado y precisado las nociones que conviene revisar en el marco de una sistematización teórica sobre dpm avanzada, aunque en constante revisión, ampliación y reformulación.

2. EL DPM: COMPLEJO POLIDISCURSIVO

Al proponer inicialmente una noción operativa de dpm, se planteó la necesidad de destacar la insuficiencia del conocimiento avanzado: "Llamaremos provisoriamente a este importante fenómeno 'discurso público mapuche', entendiéndolo como el complejo múltiple y diverso de discursos en que este pueblo, a través de sus agentes institucionales y/o representativos, apela a la sociedad mayoritaria en que está inserto con el fin de reafirmar sus principios y derechos, expresar su descontento, postular sus demandas y reivindicaciones y buscar, también, formas de acercamiento y encuentro interétnico e intercultural" (Carrasco 1996: 2).

Si bien la finalidad de este importante fenómeno sociocultural es exacta, nunca lo ha sido tanto su estatus discursivo, ya que permite suponer que se trata sólo de un conjunto de discursos variados que coinciden en una funcionalidad más o menos similar. Esto obligó a precisar la homología entre la función y el tipo discursivo del dpm, concebido en este plano como un complejo textual/discursivo ${ }^{8}$ (I. Carrasco

\footnotetext{
${ }^{8}$ Como se explicó antes, la preocupación del autor por la factibilidad del trabajo con signos verbales y por tanto su interés en
} 
1979), destacando en esta postulación teórica su potencialidad de concepción del discurso como un ente complejo, sincrético y en cierto modo heterogéneo.

En esta perspectiva, se concibió el dpm como un complejo discursivo en la medida en que se constituye como tipo de discurso conformado por varios tipos o subtipos menores dentro del sistema y que, en términos generales, presenta una instancia-emisor colectiva (organizaciones, comunidades) que a su vez configura un destinador, el pueblo mapuche, mientras que la instancia-receptor también colectiva (gobierno, instituciones) genera un gran destinatario, la sociedad winka.

Así comprendido, se trata de un complejo predominantemente verbal, en castellano con elementos del mapudungun, formado por diversas formas y tipos discursivos (comunicados, declaraciones públicas, cartas, debates, declaraciones de principios, peticiones, exigencias, panfletos promocionales, entrevistas, discurso ritual, literario, etc.), -por tanto un complejo polidiscursivo ${ }^{9}$ - que se presentan en objetos tipográficos variados (folleto, hoja, díptico, tríptico, lienzo, pared, etc.), pero que también se manifiesta en otros sistemas sígnicos, en especial suprasegmentales, visuales (lienzos, pinturas, frescos, murales) y acústicos (gritos rituales, toque de instrumentos, etc.).

Por otra parte, la potencialidad de la noción de complejo textual o discursivo permite también distinguir las interrelaciones de este tipo de discurso -el dpm- con otros tipos de discurso tradicionales anteriores (como el weupin o kollautun, el epeu míticocreencial, ciertos tipos de nütram) y también con otros discursos coetáneos provenientes de la cultura global (discurso político, discurso poético, discurso pedagógico, discurso económico), con todos los cuales se vincula por su carácter común de discursos interculturales de resistencia o, más exactamente, de discursos de resistencia intercultural.

Junto a lo anterior, se han propuesto varios rasgos que definen el dpm semánticamente en forma "transversal": 1) un discurso de orden público, especificado por rasgos del tipo de discurso producido para la prensa, además de otros del discurso político, 'académico' y epistolar con menor grado relativo de incidencia; 2) intercultural, híbrido y heterogéneo en cuanto tipo de discurso; 3) orientado a la resistencia, mantención y reforzamiento de la identidad propia, aunque ha incorporado tipos de discurso, usos y contextos de la cultura mayoritaria de la sociedad nacional; 4) de eficiencia funcional relativa, ya que el intercambio de discursos en la esfera pública se emplea como medio para alcanzar reivindicaciones y conquistas personales, culturales y socioeconómicas demandadas mediante los discursos y, al mismo tiempo, como medio de expresión simbólica de identidad, estrategia elusiva y no persuasiva en la cual el dpm adopta una función representativa o declarativa, complemento o acompañante de otros tipos de acción con propósitos empíricamente efectivos (cfr. más atrás id. 2001: 5-6).

La noción de "discurso producido para la prensa" como uno de los rasgos del dpm tampoco es casual y tiene como finalidad distinguirlo con precisión del "discurso de prensa" o discurso periodístico destacando su condición de discurso público en sentido distinto al habitual que llama "público" al discurso público que se produce en el "espacio público" ${ }^{10}$ de los medios de comunicación de masas. Siguiendo a Imbert ${ }^{11,}{ }^{12}$ consideramos que el discurso público mapuche es un tipo particular de discurso público definido por fundir lo político y lo mass mediático y por construir un sujeto socialmente preformativo, mientras que el discurso de prensa comparte sólo algunos de estos rasgos distintivos.

Desde la perspectiva de las relaciones entre instancia destinadora y contenido textual, es clara la

privilegiar el análisis sobre los textos y su proximidad en este sentido a la teoría de Schmidt, hace que con frecuencia emplee el término 'texto' en su múltiple acepción de producto, proceso y, virtualmente, sistema. Sin vulnerar esta significación, nosotros preferimos hablar aquí de "complejo discursivo" porque en este momento de los estudios en las ciencias del lenguaje el análisis de discurso emplea este último término, 'discurso', en un sentido muy similar al de texto usado con anterioridad.

${ }^{9}$ Sobre polisistemas cfr. Montserrat Iglesias (1999). En su Teoría de los Polisistemas plantea el desafío que éstos ofrecen a la literatura, lo cual hemos extendido al discurso público mapuche complementando la teoría del complejo textual de Iván Carrasco.

${ }^{10}$ Ferry y Wolton (1998), al preguntarse sobre cuáles son los principales actores de la comunicación política y de qué manera compiten en un espacio público cada vez más abierto, refieren desde distintos puntos de vista las relaciones entre espacio público, comunicación política, libertad de expresión y democracia. A esto Wolton agrega que uno de los roles del espacio público es vigilar el equilibrio entre información, comunicación y representación, a lo que puede agregarse que las relaciones interculturales también debe incorporarse en este equilibrio.

${ }^{11}$ Dice Imbert (1984:165): "El sujeto que se realiza en el discurso social, lo hace instituyendo un espacio público, espacio en el que se escenifica la sociedad a través de sus portavoces. Contribuye así a la formación de un discurso público que define un espacio común a diferentes sujetos sociales, espacio semiótico de la sociedad, lugar de intercambio de los discursos y de plasmación de la identidad, mediante el cual los individuos manifiestan su adhesión formal a los sistemas de intercambio y su participación en los sistemas de valores.

12 "De la conjunción de lo político y lo mass mediático surge un discurso público cuyo objetivo es el carácter socialmente performativo del sujeto. De ahí que lo importante estribe en la adquisición de la competencia emisiva" (Imbert id. ant. 167). 
diferencia entre dpm cuya instancia destinador está formada por dirigentes y representantes de este pueblo que refieren un contenido propio y el discurso de prensa cuya instancia destinador es winka o no mapuche y habla acerca de aspectos de la sociedad mapuche en su relación con la sociedad mayoritaria. Por este motivo, se trata de fenómenos distintos, cuya naturaleza, propósitos y estrategias son opuestos entre sí, y lo único que tienen en común aparte de referirse a la misma temática es su difusión a través de un espacio público, por lo que presentan diferencias discursivas, narrativas, actanciales y valóricas entre sí.

En cuanto a los aspectos todavía no desarrollados, es necesario reconocer que salvo algunas observaciones insuficientes los criterios para definir cómo distinguir, asignar y designar el discurso base o central y los discursos complementarios en los complejos textuales públicos mapuches se han olvidado. En efecto, sólo en (2002:9) se hace una breve observación al respecto que no aclara el problema: "Desde otra perspectiva, que ahora no se desarrolla, el discurso base del complejo textual toma la designación de la clase de discurso específico que corresponde en cada caso: declaración, comunicado, carta, etc., y los discursos complementarios asumen los otros tipos de discurso incorporados, tanto de los tipos discursivos que conforman el mismo discurso público como de otras categorías posibles y cuya presencia es también efectivamente clara en el discurso público mapuche: discursos narrativos, declarativos, expositivos, explicativos, argumentativos y apelativos (cfr. al respecto Carrasco 1998:211)".

\section{LOS TIPOS DISCURSIVOS DEL DPM}

Las clases y tipos de discurso del dpm se han analizado con varios corpus distintos, de los cuales los resultados de dos de ellos han sido mayormente difundidos.

El primer análisis fue hecho a partir de un corpus de 300 textos recopilados. Según el estudio (cfr. Carrasco y Sepúlveda 1999) se pudo precisar que las clases del dpm de acuerdo a la denominación de los productores del texto son las que siguen.

a) Declaración Pública: clase de discurso mayoritaria, 32,73\%; subclasificada en Declaración Pública $(43,02 \%)$, Declaración a secas $(13,44 \%)$, Declaración de Prensa $(17,20 \%)$ y Declaración Mapuche $(5,37 \%)$.

b) Comunicado: 26,19\%, dividido en Comunicado (56\%), Comunicado de Prensa (32,2\%), Comunicado Mapuche $(11,8 \%)$.

c) Carta: $18,45 \%$, con variantes Carta Abierta (52,4\%) y Carta Cerrada (47,6\%).

d) Manifiesto: $0,59 \%$ sin variantes.

e) Convocatoria: $0,59 \%$ sin variantes.

f) Documentos, Propuestas y Similares: $5,95 \%$.

g) Boletines, Revistas y Similares: 6,54\%.

h) Conclusiones Asambleas, Congresos y Similares: 1,19\%.

i) Varios: textos no identificables $4,76 \%$.

A nivel de las superestructuras ${ }^{13}$ y con relación a la categoría Declaración Pública, se produce aquí un fenómeno que después se repetirá con respecto a otros tipos de discurso como la carta, el comunicado y otras, la "declaración pública mapuche", proceso de apropiación mediante la transacción o extensión de un rasgo distintivo propio a un discurso ajeno a la cultura mapuche se le atribuye identidad propia "Mapuche" (ver por ejemplo T47, o los "comunicados mapuches" T79 o T85, o la "opinión política mapuche" T139). Se trata sin duda de un esfuerzo textual de otorgar identidad propia a los discursos asumidos desde la cultura externa (cfr. Carrasco 2001 y Otazo 2001).

Al analizar estos datos, se observa que en cuanto tipos de discurso dos de ellos, declaración pública y comunicado, corresponden a textos cercanos al discurso de prensa o periodístico, 58,92\% ${ }^{14}$; manifiestos, convocatorias y propuestas se acercan más al discurso político, $7,13 \%{ }^{15}$; documentos, boletines,

\footnotetext{
${ }^{13}$ Para los conceptos de superestructura/macroestructura y otros relacionados, cfr. van Dijk 1989 o 1990.

${ }^{14}$ Conviene destacar que el dpm es el producido por los propios mapuches, por lo que nos permite conocer directamente su punto de vista propio y difiere por ello de la percepción construida por el discurso de prensa sostenido por los periodistas, y aunque los medios de comunicación masiva son su principal canal de difusión (por lo que nosotros lo caracterizamos como discurso "para la prensa" o "para los medios"), el dpm se expresa también en panfletos, pancartas, pintura y rayado de paredes, graffiti, gritos simbólicos, toque de instrumentos, etc.

15 En realidad, el sentido final de todo el discurso público mapuche es de orientación política y resultados políticos, lo que es evidente en los tipos de discurso que lo conforman y sobre todo en la forma en que los estructura y emplea.
} 
conclusiones y otros convencionalmente se incluyen en un "discurso académico", 7,73\%, que exige operaciones intelectuales sistemáticas homólogas a las universitarias y similares y, por último, carta abierta y cerrada se incluyen con facilidad en el tipo discursivo carta 47,6\%, diverso a los anteriores.

Así, el dpm se halla conformado por 4 tipos de discurso, discurso para la prensa, político, "académico" y epistolar, compuestos a su vez por otros discursos ya señalados, lo que demuestra claramente su carácter de complejo polidiscursivo discutido más atrás y permite al mismo tiempo diferenciarlo de cada uno de ellos, o de otros ${ }^{16}$.

Posteriormente, con 543 textos procesados los resultados no varían substancialmente (2002, id. ant.) y se encuentran sólo algunas subcategorías nuevas como Denuncias, Comunicado Urgente, Carta Pública algunas de mayor interés como Carta Mapuche, ya comentada. Cantidades y porcentajes son similares a los anteriores. Declaración Pública 117 21,5\%; Comunicado 248 45,7\%, los porcentajes más altos, otro resultado interesante; Carta 90 16,6\%; Manifiesto 1 0,2\%; Documentos y otros 39 7,2; Revistas y otros 31 5,7\%; Propuestas y otros 39 7,2; Conclusiones Asambleas y otros 2 0,4\%; Convocatoria 5 0,9\%; Varios 10 1,8\%. Los tipos discursivos tampoco varían mucho. Discurso para la Prensa (Declaración Pública y Comunicado): 58,92\% y 68,58 incluyendo Carta Abierta; Discurso Político (Manifiesto, Convocatoria, Propuesta): 7,13\%, y Discurso Académico (Revistas, Conclusiones): 7,73\%. Como puede verse, aquí la categoría Carta Abierta se ha incluido en el Discurso para la Prensa por su carácter público en tanto que Carta Cerrada se ha excluido.

Como se ha reiterado, estos datos muestran con claridad las clases/tipos de discurso que conforman el dpm y cómo se encuentra organizado en cuanto complejo polidiscursivo público, mapuche e híbrido. Al no constituir un sistema cerrado, sino un complejo polisistémico, en su condición discursiva puede emplear y emplea los criterios tradicionales de la cultura textual mapuche y los modernos y especializados de la cultura textual pública de la sociedad mayoritaria, para lo cual debe asumir las "transacciones" necesarias "entre un discurso que no les es propio y uno que deben construir para poder comunicarse dentro de los esquemas de la otra cultura, lo que también constituye una forma del "trafkiñ" propio de la cultura tradicional y del cual hemos observado en los discursos míticos su empleo como categoría supradiscursiva" (Carrasco 2000: 155).

De esta manera, la lógica ${ }^{17}$ que lo identifica en cuanto discurso híbrido y complejo polidiscursivo intercultural se proyecta también en su función performativa ${ }^{18}$ indigenista y autoidentificatoria, en el marco de relaciones de resistencia principalmente conflictuales con la sociedad mayoritaria opresora, discriminadora y marginalizadora, rasgos que caracterizan la actitud de la instancia emisora/destinadora del discurso junto con otras que buscan el acercamiento y encuentro intercultural mediante la modificación de la actitud del otro legítimamente distinto y cierta flexibilización de la actitud propia reforzada por el empleo de creencias tradicionales propias y conocimientos modernos ajenos.

\section{EL DISCURSO PÚBLICO MAPUCHE ESTUDIANTIL UNIVERSITARIO}

4.1. Antecedentes generales. En el pueblo mapuche existe un movimiento estudiantil mapuche organizado, con antecedentes de demandas educativas desde principios del siglo XX hechas por organizaciones como la Sociedad Caupolicán Defensora de La Araucanía (Foerster y Montecino 1988). Posteriormente, se crean instituciones como la Dirección de Asuntos Indígenas, el Instituto de Educación Mapuche "Pelontuwe", la Confederación de Sociedades Mapuche, el Instituto de Desarrollo Indígena, etc. en medio de cuya gestión se reconoce que las acciones de lucha estudiantil tienen mayores espacios participativos, lo que incide en la influencia de la Federación de Estudiantes Indígenas, por ejemplo, en la creación del Hogar de Estudiantes Mapuche.

Más adelante, a través de la creación de la CEPI el año 1991 y, después, la CONADI, los gobiernos democráticos han canalizado su preocupación por el tema de los hogares estudiantiles, aportando recursos fiscales para su financiamiento ${ }^{19}$. 1997 es señalado por los estudiantes como un año relevante, desde el

\footnotetext{
${ }^{16}$ En Comunicación y Medios $\mathrm{N}^{\mathrm{0}}$ 13, 2002, se complementa y completa el análisis del dpm en cuanto complejo discursivo o textual polisistémico y en su carácter de discurso producido para la prensa u otros medios públicos.

17 Carrasco 1998.

${ }^{18}$ Cfr. Imbert 1984.

${ }^{19}$ Los estudiantes señalan que las movilizaciones de estudiantes del año 1997 han sido las reales gestoras en la asignación de recursos y que han logrado mantener vigente el tema de los hogares de estudiantes mapuches universitarios.
} 
cual la lucha como movimiento estudiantil se ha desarrollado con gran fuerza, formando parte de la línea de continuidad histórica de un proceso de demandas aún no resueltas e iniciadas desde el ingreso de jóvenes mapuches al sistema educacional chileno. En los últimos años, el movimiento de estudiantes mapuches ha realizado permanentes luchas en la consecución de hogares; su reorganización interna les ha posibilitado actuar decisivamente en el quehacer político del pueblo mapuche y, consecuentemente, fortalecer sus niveles de organización y participación en él.

Las movilizaciones estudiantiles pueden situarse en dos grandes escenarios con una característica común, el conflicto: a) la lucha por la consecución de hogares y superar los problemas que impiden satisfacer estas demandas (falta de presupuesto, ausencia de voluntad política de las autoridades, incumplimiento de acuerdos, y otros); b) la lucha por ser considerados y respetados como pueblo o nación mapuche, expresado en apoyo a comunidades en conflicto, respaldo a presos políticos, denuncias sobre injusticias y persecución del Estado chileno y acciones de reivindicación territorial.

Cabe señalar que los estudiantes sostienen que estas dos grandes líneas de acción son asumidas por ellos como pueblo, lo que explica que sus producciones discursivas se presenten como instancias emisivas colectivas, de voz plural -los estudiantes mapuches- y representativas de un destinador subyacente -el pueblo mapuche- quien, en definitiva, es el que denuncia, acusa y apela en el discurso.

Este discurso público mapuche estudiantil universitario, en adelante dpm-eu, es mayoritariamente textualizado a través del Discurso para la Prensa y las clases textuales Comunicado y Declaración Pública, también mayoritarias; otros textos menos socorridos corresponden a Cartas y Documentos de Análisis. La mayoría de estos textos son autodenominados por sus emisores, por ejemplo, "Declaración Mapuche", "Comunicado del Hogar Pehuenche", "Análisis de Coyuntura Mapuche".

Los diferentes tipos discursivos que constituyen el discurso público de los estudiantes mapuches y que son el discurso base del complejo textual, a su vez, están formados por discursos complementarios (Carrasco, I., 1998) expositivos, argumentativos, apelativos, declarativos, explicativos, entre otros. El emisor textual acude, por ejemplo, al discurso expositivo para dar cuenta de una variedad de situaciones que le afectan y a la vez involucra hechos que las ratifican. Por su parte, la presencia del discurso argumentativo se expresa en la exposición de hechos que en sí mismos constituyen argumentaciones propiamente tales; hechos y argumentos contienen rasgos identitarios, culturales e históricos relevantes y, con ellos, la presencia menor pero no menos importante de argumentos éticos y políticos, entre otros.

Los autores empíricos de estos textos son agrupaciones estudiantiles, dirigentes y/o representantes mapuches, quienes se dirigen a la opinión pública, principalmente para dar a conocer sus demandas, denunciar injusticias, reforzar su identidad, dar a conocer los problemas con la sociedad mayoritaria, actualizando mediante el discurso las relaciones de conflicto entre sociedad mapuche y sociedad mayoritaria.

Carrasco (1996) destaca el rasgo identitario en los movimientos reivindicatorios mapuches y la actitud performativa, apelativa y conflictual del discurso público, junto a su carácter intercultural de demanda a la sociedad chilena, características todas presentes en el discurso público mapuche ${ }^{20}$. En este sentido el componente identitario se destaca en los argumentos (históricos, culturales éticos, entre otros); en los problemas expuestos, en los hechos descritos, etc. La finalización de los textos incluye casi siempre frases de aliento, lengua mapuche, mapudungun, consignas mapuches, la identificación del origen del texto y de los emisores, fenómeno que al mismo tiempo sugiere significados relacionados con la historia de convivencia conflictuada entre dos pueblos, por ejemplo: "Desde Temuco Territorio Mapuche"; "Desde el Puelmapu"; "Desde la capital del Estado opresor".

El tópico transversal a los discursos es el propósito de autodeterminación, sustentado en las relaciones asimétricas con la otra sociedad, temática propiciadora de un discurso con orientación intracultural y, a la vez, coexistiendo con éste un discurso ubicado en el ámbito estudiantil (a pesar de que siempre se advierte un planteamiento de pueblo) donde se textualizan problemáticas relacionadas con políticas de financiamiento de hogares y políticas públicas de educación (las cuales se inscriben en la llamada "demanda histórica") y que pasan por la lucha territorial, aspectos en los que el discurso de los estudiantes se sustenta y por lo que deben llamar a su pueblo; sin embargo, este ámbito temático genera un discurso intercultural en el que se involucra a la cultura ajena como responsable de estas soluciones, sin dejar de manifestar que como hasta ahora no ha existido voluntad para ello, es necesario que el pueblo mapuche tome sus propias decisiones, autónomamente.

4.2. La superestructura del dpm estudiantil universitario. Lo anterior hace necesario referirse a la

\footnotetext{
${ }^{20}$ La presencia de estos rasgos en el dpm-eu fue investigada por Sonia Betancour en el trabajo de Tesis 2005 ya citado.
} 
superestructura del discurso público de los estudiantes, estudio basado en la propuesta de Carrasco $(2001 / 2003)^{21}$ y desarrollado por Betancour (2005). El discurso de los estudiantes contiene las nueve instancias reconocidas por Carrasco y, globalmente, presenta las siguientes características:

En el Protocolo de Apertura, la situación enunciativa es variada; contiene, por ejemplo, un emisor genérico explícito (estudiantes mapuches) que se dirige a un receptor explícito no mapuche (opinión pública) y a un receptor mapuche minoritario, simultáneamente. En otras oportunidades el discurso va dirigido únicamente a un receptor no mapuche y, en algunos casos, no identificado.

Hay textos en los que no hay definición de la situación enunciativa; éstos se inician con la identificación de la clase textual, o la entidad emisora que debiera estar en el Protocolo de Apertura se halla en la instancia Inicio del texto (situación advertida por Hugo Carrasco en su oportunidad). En la mayoría de los textos estudiados no hay una actitud clara y explícita acerca del tema enfrentado, como correspondería que la hubiera en esta primera instancia de la superestructura.

La instancia Inicio, en su mayoría, contiene la clase textual identificada por los emisores, y en algunos textos se agrega a la clase textual alguna adjetivación identitaria mapuche o el tema global del texto o la fecha del documento.

La instancia presentación del Problema está normalmente incluida en los Hechos, por lo general están mezclados con argumentos variados, juicios y valoraciones sustentados en bases históricas, identitarias o similares (situadas siempre al interior de la cultura) que sugieren significados aclaratorios de las causas (la sociedad mayoritaria) por las cuales el pueblo mapuche tiene problemas.

El Metadiscurso Mapuche contiene la postura del pueblo mapuche de modo relevante y se apoya en valores propios, de base histórica. En esta instancia el discurso de los estudiantes pone gran énfasis en la "deuda histórica" del Estado chileno con el pueblo mapuche y en la "configuración de la Nación Mapuche".

La instancia Resumen no está siempre presente en los textos estudiados.

La Apelación presenta un énfasis importante hacia la cultura propia. El discurso apela a su pueblo permanentemente instándolo a actuar, a permanecer en la lucha a defender sus derechos; sobre todo, el derecho a ser legítimamente reconocido como pueblo nación mapuche, por tanto, a la libre determinación como tal. También apela, casi siempre de modo indirecto, a la cultura mayoritaria, para encararle incumplimientos de acuerdos pactados y para reafirmar ante ellos su postura como pueblo. En esta instancia es notoria y significativa la apelación a la cultura propia, la cual se refrenda con idioma mapudungun, frases de aliento y llamados a la lucha por la "causa mapuche". El discurso involucra a la cultura ajena a modo de evidenciar a la cultura propia las injusticias cometidas contra su pueblo y cómo de modo permanente continúa la discriminación y la negativa de ver al pueblo mapuche como un legítimo pueblo. Llama la atención la forma indirecta que asume el discurso para referirse a la sociedad mayoritaria, sugiriendo que no espera respuesta de la misma.

En el Código de Cierre hay casos en los que no reaparece la instancia emisora, ni receptora más que de modo impersonal; otras situaciones están dadas por la aparición de un receptor definido mapuche (hermanos mapuche, comunidad mapuche), distinto del receptor inicial de los textos (receptor no mapuche) y un último caso dado por la reaparición del receptor inicial.

La instancia Finalización involucra elementos identitarios, como lugares, grafías mapudungun, en algunos casos, y el nombre de los autores empíricos de los textos.

En definitiva y globalmente, la superestructura del discurso público de los estudiantes mapuches no presenta variaciones relevantes y/o significativas respecto de las señaladas en los estudios sobre discurso público mapuche en general; asume la mayoría de sus rasgos en las diferentes instancias que lo componen. El único rasgo distintivo que posee es la orientación intracultural del discurso, la cual subyace a lo largo de él, y se evidencia con énfasis en la instancia Apelación.

4.3. La macroestructura semántica. En cuanto a la macroestructura semántica, el dpm-eu refiere conflictos de demandas territoriales, reconocimiento de su legitimidad como pueblo y aspectos identitarios, demandados por los distintas organizaciones mapuches y que los estudiantes asumen como propios, sumando demandas estudiantiles como hogares y acceso igualitario a la educación, entre otros, que también son demandas planteadas como pueblo mapuche a la sociedad mayoritaria; los discursos involucran la contingencia de estas relaciones, poniendo no obstante de manifiesto una actitud dialógica

${ }^{21}$ El autor señala que en el nivel sintagmático hay 9 instancias que se relacionan entre sí; éstas son Protocolo de Apertura, Inicio, Problema, Hechos, Metadiscurso Mapuche, Resumen, Apelación, Finalización, Protocolo de Cierre. Para no redundar en detalles, sólo se mencionan aquí globalmente las diferentes instancias, poniendo énfasis en la instancia Apelación que es donde el discurso de los estudiantes presenta particularidades intraculturales. 
con la cultura propia y no con la cultura ajena, a quien involucra denunciando sus acciones en forma indirecta. Es un discurso que postula una etapa de reencuentro y confianza en la cultura propia para la solución de los problemas que los aquejan, declarando que sólo con la autonomía como pueblo será posible la superación de los conflictos con la sociedad mayoritaria.

Se genera, sin duda, un discurso público intercultural pero orientado a encontrar soluciones que, según el sujeto cultural mapuche, ya no dependen de las relaciones con la otra cultura, sino de la cultura propia y de ahí el énfasis intracultural del mismo.

El discurso constituye un conjunto de tópicos con una línea temática transversal -las relaciones de conflicto con la sociedad mayoritaria y la consecuente lucha por sus derechos como pueblo-, que se pueden resumir como: repudio a actuaciones del Estado chileno por permanente tratamiento injusto al pueblo mapuche, criminalizando acciones legítimas de éste; lucha por la autonomía y respeto a su derecho de libre determinación como pueblo; compromiso y apoyo solidario respecto de los diferentes problemas que aquejan al pueblo mapuche (presos políticos, represas, persecuciones, políticas de Estado, entre otros); denuncias de atropellos, xenofobia e invisibilidad impuesta al pueblo mapuche; demanda por la formación de la "Nación Mapuche" con fuerte llamado intracultural al compromiso por esta causa y al fortalecimiento de su identidad.

Estos tópicos están presentes en las distintas clases textuales del discurso público de los estudiantes, en los que subyace, en definitiva, el desconocimiento o indiferencia y el prejuicio de la sociedad mayoritaria respecto del pueblo mapuche y su cultura y que, de hecho, se expresan en la carencia de armonía con el sentir y ser cultural mapuche contraposiciones entre progreso, globalización y modernidad en la cultura mayoritaria y tradición, identidad y ancestro de la cultura mapuche, fenómeno con el que colaboran políticas de Estado (económicas, educacionales, culturales, etc.), tampoco compartidas y orientadas a un tipo de sociedad que no se compadece con la mapuche.

4.4. Los rasgos transversales del dpm estudiantil universitario. Por otra parte, el discurso de los estudiantes asume las características definitorias del dpm: complejo discursivo, hibridez, heterogeneidad, performatividad.

El carácter híbrido y heterogéneo del discurso público mapuche es estimado como una categoría de los discursos interculturales a propósito de la coexistencia de culturas distintas y el contacto entre ellas de modo permanente (Carrasco, 2000-2002), carácter que también se advierte en el discurso de los estudiantes, como asimismo los rasgos de heterogeneidad y performatividad del discurso. La denominación de las clases textuales, mezcla elementos de cultura propia con elementos de la cultura ajena, como "Declaración/Mapuche". También es mixta la estructuración discursiva de los textos, que pueden empezar como Comunicado y finalizar como Carta.

Por otra parte, las macroestructuras semánticas contienen reiterados tópicos que refieren a conflictos originados en las relaciones con la sociedad global y variedad de formas de enfrentamiento de los problemas que afectan al pueblo mapuche, entre otras.

Por último, en el discurso de los estudiantes, hay rasgos importantes de hibridez en la superestructura de los textos, los que por una parte mantienen su organización al modo de la retórica clásica (Carrasco 2000 , 2002) y, por otra, expresan variaciones. Hay una conjunción de elementos emotivos y racionales con el fin de conmover, confundidos y entremezclados con elementos pasionales y expositivos, por ejemplo: "Hoy miércoles 28 de agosto cumplen 20 días en huelga de hambre (...), todos recluidos injustamente en la cárcel (...), quienes hoy, en pleno siglo XXI, deben hipotecar su vida para clamar y hacer valer su derecho" (Decl. 28/08/02).

La performatividad del discurso estudiantil se expresa en enunciados performativos con deícticos de primera persona plural y en presente, como, "apoyamos la movilización; repudiamos la actitud violenta; denunciamos la persecución; hacemos un llamado", etc. (Decl. 15/09/02; Com. mayo, 2003; Com. 24/10/2003).

Si se admite que el sujeto emisor de la enunciación se expresa involucrado estrechamente con el enunciado que emite, esto se vincula también a que la instancia emisiva del discurso público de los estudiantes mapuches universitarios se manifiesta representando al pueblo mapuche, lo que lo autoriza a generar un discurso cuya voz apela, denuncia, repudia, exige, etc., intentando producir efectos que sirvan a los propósitos intraculturales del discurso y, al hacerlo de modo relevante respecto de la cultura propia, podemos decir que este discurso manifiesta un rasgo particular del carácter performativo del discurso público mapuche. 
Al atender a la instancia de producción y recepción de los textos, como se ha adelantado, se advierte un destinador plural implícito (el pueblo mapuche) representado por un emisor textual explícito y colectivo directo que asume su voz (organizaciones estudiantiles universitarias mapuches) y que se atribuye su representación, pero que a la vez es parte de aquello que representa. García (2000) señala que "al interior del actual discurso público mapuche se construye una autorrepresentación simbólica del emisor como voz cultural autorizada en la relación intercultural", rasgo coincidente con el discurso público de los estudiantes mapuches. Es un emisor que se siente con el deber de defender a su pueblo, a su identidad y denunciar los problemas que los aquejan, pero sobre todo es quien llama al propio grupo cultural a comprometerse con su historia, evidenciando el paso a otra etapa de esta lucha, ubicándola en su propio espacio, al interior de la cultura propia; esto se puede ver reforzado, por ejemplo, con el uso del idioma propio, el mapudungun, al finalizar los textos y frases simbólicas de lucha.

Se trata de un discurso cuya instancia comunicativa es compleja e interesante, pues si bien hay un emisor mapuche que se dirige a un receptor explícito, la opinión pública, ambos representan a instancias implícitas, estrategia discursiva de la cual se sirve para dar cuenta de las problemáticas que lo afectan como pueblo, mostrando el origen y causa de los conflictos que lo afligen en la sociedad mayoritaria, y, así, dirigir su discurso apelativo al propio pueblo, a la propia cultura, con un llamado a tomar conciencia de que es tiempo de comprometerse, de luchar y de lograr la autodeterminación. De este modo es como el discurso incorpora al destinatario explícito mapuche (por ejemplo, "Nuestro hogar se encuentra con el deber moral y político de informar a las comunidades mapuche, al pueblo de Chile y a la comunidad internacional lo siguiente"), aunque de presencia minoritaria, coexistiendo con el otro, pero destacando una enfática apelación al pueblo mapuche en la parte final de los textos, lo que hace advertir la importancia del destinatario mapuche, por ejemplo, "somos los indígenas quienes debemos dirigir el futuro de nuestro pueblos en lo que son territorio, autonomía $y$ administración pública-estatal" (Comunicado 18/12/2005).

El destinatario mapuche se nombra como "comunidades mapuche", "hermanos mapuche", o "las nuevas generaciones de mapuche", esto último en un Documento de análisis. Son comunes los textos en los que, si bien en el Protocolo de Apertura el receptor es la opinión pública, en la instancia Apelación no es éste a quien se apela, sino al pueblo mapuche, quien es apelado para actuar frente a los conflictos que lo aquejan. En la Finalización, el receptor no sólo ratifica su postura denunciante y de lucha, sino también el por qué de esas acciones, a modo de convencimiento o persuasión, agregando frases en idioma mapudungun y español, llamando a la acción, por ejemplo:

“iAMULEPE TAIÑ WEICHAN. MARICHIWEU.WEWAIÑ PU PEÑI KA PU LAMGEN NEWENTUAIÑ! (Nuestra lucha continúa. Diez veces venceremos, todos juntos vamos a vencer, hermanos y hermanas, lo haremos todos con fuerza)" (Comunicado Público, 12/04/2006 Hogar de Estudiantes Mapuche PvramPeyvn Zugu).

Se puede agregar que la traducción del texto al español sugiere una conciencia intercultural de la instancia destinadora, consciente de la otra cultura, pero dirigiéndose directamente a la propia para actuar sobre aquélla, por lo que estas expresiones traducidas al español alcanzan una función educativa y al mismo tiempo el cumplimiento del objetivo primero u originario del discurso, como se ha dicho, el llamado en el idioma propio, a hacerse cargo de la lucha de su pueblo.

En definitiva, la instancia emisora de los textos, que representa a un destinador mapuche, se dirige a una instancia destinataria mapuche para actuar sobre una no mapuche, representativas de destinatarios subyacentes (sociedad mapuche/sociedad global). No obstante, se aprecia la sociedad mapuche como el destinatario defectivo para los propósitos del discurso, enfáticamente apelado y validado en la Finalización y Cierre de los textos. Del destinatario no mapuche, no se espera respuesta, cuestión que puede ser ratificada con el estudio de las macroestructuras semánticas de los textos ${ }^{22}$, donde los diferentes discursos formantes del polisistema están orientados a mostrar la realidad inconfortable del pueblo mapuche como consecuencia de las relaciones asimétricas (injustas, asimilatorias, marginalizadoras, ilegítimas) con la sociedad global, quien lo ha invisibilizado con sus políticas integracionistas, excluyentes, discriminatorias y acuerdos pactados y no cumplidos, por lo que ya no se cree ni se espera nada del Estado chileno y resulta imperativo llamar al propio pueblo a reorganizarse y luchar por sus derechos. Consecuentemente, la sociedad mayoritaria, como destinataria, adquiere una dimensión

\footnotetext{
${ }^{22}$ Betancour 2005, cit.
} 
significativa distinta de la original y por la cual es involucrada en el discurso intercultural: “...apela a la sociedad mayoritaria con el fin de reafirmar sus principios...", etc. Este nuevo significado desplaza la función activa reivindicatoria otorgada por la apelación del discurso intercultural en un escenario de conflicto (sociedad mapuche/sociedad mayoritaria), hacia una función pasiva, pero importante, que evidencia una etapa cursada, no resuelta y negativa, en un escenario de lucha cuyo protagonista es la sociedad mapuche quien, con los suyos, se autoprovee de lo que necesita como pueblo, acudiendo a un discurso de apelación intracultural e, indirectamente, intercultural con la sociedad global.

Es un discurso que, si bien contiene las relaciones de conflicto con el sector mayoritario de la sociedad, también de algún modo colabora en su resolución; esto es, denunciando el maltrato, pero al mismo tiempo acercándose a través de la manifestación explícita e implícita del deseo de reconocimiento y respeto como pueblo por parte de aquélla. La instancia destinadora reclama, a través de formas discursivas indirectas, la invisibilidad impuesta y opresora que no les permite un reconocimiento legítimo y que se plasma en el discurso en una actitud emisiva orientada a la cultura propia a quien da cuenta de esta realidad inconfortable para asirse de ella y apelar a su propia cultura por una participación comprometida en la lucha por la autonomía.

Esta condición que presenta el discurso de los estudiantes universitarios, nos permite señalar su importancia como proceso de comunicación intercultural e intracultural. La instancia destinadora se constituye en portavoz de su pueblo y surge como resultado de ser parte culturalmente involucrada en la contingencia de las relaciones interétnicas e interculturales con la sociedad mayoritaria. Es una instancia que pone de manifiesto un discurso con una voz plural "nosotros, el pueblo mapuche", con plena conciencia de su ser cultural y del ser de la cultura ajena, donde distingue a aquellos que no forman parte de este conflicto y que los ve positivamente.

Al respecto, Contreras (2000) sostiene que en los dpm mapuches, y debido a la fuerte y decisiva presencia del tema de la tierra, hay "diferentes tipos de destinatarios, como aquellos positivos", o sea, los que comparten o se suman a la 'causa mapuche': "hermanos y hermanas mapuches que se adscriben a ella". Citando a Verón (1987), llama "prodestinatarios a los que asumen el colectivo de identificación"; "paradestinatarios" a quienes aún no tienen una postura definida y sobre los cuales se pretende influir; y "contradestinatario" a quien "no comparte la causa mapuche o la reconoce como falsa (instancias gubernamentales, la sociedad, la cultura).

En el dpm-eu hay un contradestinatario al interior de la cultura que no comparte las luchas mapuches y colabora con la sociedad mayoritaria contra su propio pueblo. El mismo discurso los denuncia "No obstante, en el pueblo mapuche siempre han existido los yanakonas"; "Aparte de los enemigos de siempre (...), se suman hermanos" (Comunicado Público, 04/12/2002); "El hecho de que Sofía Painequeo (yanacona) enseñara mapudungun a personajes del Ejército y de la Iglesia, nos da un claro indicio de la preparación que realizan" (Declaración Mapuche sobre el 18 de septiembre). También los hay en la sociedad chilena global y, sin duda, mayoritario: autoridades, fuerzas policiales, personas o sectores de Gobierno, el Estado, sus políticas, leyes, etc.

Los prodestinatarios son apelados a continuar las luchas (presos políticos, estudiantes, entre otros), y demás "hermanos"mapuches; los paradestinatarios son minoritarios, pero están reforzando el llamado a la cultura propia, por ejemplo, a "los hermanos que aun no despiertan del letargo logren liberarse del miedo al sistema"(Declaración Mapuche, Agrupación de Estudiantes Mapuche Trawün Wekeche).

La instancia comunicativa del discurso asume actitudes emisivas variadas. Persuade, explica, apela, reprende a los de cultura propia. A los que aún no participan activamente, los llama a la reflexión, les da tiempo para que cambien su actitud de letargo y, finalmente, los comprende en el contexto de la sociedad global. A la cultura ajena, los enjuicia, los califica con dureza "invasor", “opresor", "usurpador", pero también asume una actitud emisiva de justicia, distinguiendo que no son todos iguales: "Recalcamos que nuestra lucha no es contra el pueblo chileno como tal, sino contra la clase oligárquica dominante que pretende con su democracia de papel hacer creer que el 'cambio es posible' o que... etc." (Decl. Agrupación de Estudiantes Mapuche). En todo caso, el destinador puntualiza respecto de quiénes son los "enemigos de siempre" (estado, empresarios, forestales, medios, la comunicación, justicia chilena racista).

La instancia destinadora se reconoce mapuche y participante activa de su cultura, de su etnia, de su sentir como pueblo. Al respecto, García (2000) precisa que "la experiencia que el sujeto productor del discurso tiene sobre su propia identidad étnica es textualizada a través del reconocimiento explícito de pertenencia a un grupo primario, la cultura mapuche y a la autoatribución que sobre sí realiza como voz cultural autorizada en el marco de las interactuaciones interétnicas e interculturales"; hay también un emisor institucionalizado en los discursos, un 'yo' inclusivo y extensivo en el 'nosotros', en los textos del tipo Comunicado, Declaraciones, Cartas y Propuestas. En los textos de Análisis, si bien hay un destinador 
individual, igualmente asume una voz plural "nosotros" (un yo inclusivo y extensivo en el nosotros).

Lo relevante de la instancia destinadora del dpm-eu es su notoria orientación intracultural: el espacio textual es un medio para dar cuenta de un acontecer insatisfactorio en el transcurso del tiempo y cuyo origen está en las relaciones con la cultura ajena, lo que el pueblo mapuche debe tener claro, concientizarlo y asumir una actitud de autonomía que depende de la actitud y compromiso de su propio pueblo. Es un destinador convencido y consciente de su lucha y de sus propósitos: "Lo hacemos con la convicción de que nuestros esfuerzos y sacrificio es no sólo por nosotros, sino también por todos nuestro pueblo y futuras generaciones" (Decl. 27/08/2003 Hogar Mapuche We Liwen de Valdivia); "Nada podrá detener nuestra conciencia de Pueblo Nación Mapuche luchando por la libertad y recuperación de nuestro territorio ancestral" (Com. Coordinadora de Hogares Estudiantiles Mapuche, IX y X regiones).

El destinador discursivo conoce cómo opera la sociedad mayoritaria en el quehacer político, social, cultural y en las relaciones con la cultura minoritaria, sabe de su historia común como parte involucrada y afectada, y se apropia de sus espacios, que no son los de él porque "nosotros no pertenecemos ni perteneceremos a la nación chilena, simplemente somos parte de la Nación Mapuche"; y de los discursos sirviéndose de ellos para decirle a su pueblo que es el momento de unirse y luchar por una causa común y trascendente. El sujeto destinador refiere sus objetivos, explica el motivo de su lucha a los de su pueblo y alienta a participar de esta historia: "el pueblo mapuche sigue en pie. Hoy con nuevos aires, con más fundamentos y nuevos hijos conscientes del verdadero papel que nos toca en esta historia $y$ de que lo que hoy se lleva adelante no podrá terminar hasta desembocar en la autodeterminación (...) cuando el pasado, presente y futuro de nuestro pueblo flamee en cada corazón mapuche y los hermanos que aun no despiertan del letargo logren liberarse del miedo al sistema, la cuarta historia será realidad, la batalla final habrá comenzado" (Declaración Agrupación Trawün Wekeche).

En definitiva, es un destinador con una actitud comunicativa de permanente búsqueda y acercamiento a destinatarios intraculturales con un discurso persuasor de argumentos culturales e históricos propios, reforzados por relaciones conflictuales con la otra sociedad; informado, consciente, comprometido y que en la otra sociedad distingue a quienes buscan oprimirlos e invisibilizarlos como pueblo. Asimismo sabe quienes de su cultura no participan comprometidamente en ella y los llama a la reflexión concibiéndolos en el contexto de la sociedad global y de las relaciones complejas en que se desarrollan, por lo que les recuerda su historia y da cuenta de su proyecto final.

\section{CONCLUSIONES. LA ORIENTACIÓN INTRACULTURAL DEL DPM ESTUDIANTIL UNIVERSITARIO}

Al revisar la noción de discurso público mapuche propuesta por los estudios como "Complejo múltiple y diverso de discursos en que este pueblo, a través de sus agentes institucionales y/o representativos, apela a la sociedad mayoritaria en que está inserto con el fin de reafirmar sus principios y derechos, expresar su descontento, postular sus demandas y reivindicaciones y buscar, también, formas de acercamiento y encuentro interétnico e intercultural" (Carrasco 1996: 2), (destacado nuestro) debemos hacer algunos alcances respecto del rasgo preformativo del mismo que precisen y/o expliquen la presencia del componente intracultural del discurso apelativo producido por los estudiantes.

Si el discurso público mapuche se origina en las relaciones de conflicto entre sociedad mapuche y sociedad mayoritaria, generándose un discurso intercultural y, consecuentemente, apelativo hacia esta última, cabe preguntarnos ¿qué sentido tiene en este contexto el componente intracultural del discurso público de los estudiantes?

La presencia de las relaciones interétnicas e interculturales se expresa en un espacio textual que asume la contingencia sociocultural e histórica del pueblo mapuche y su relación conflictual y conflictuada con el Estado chileno, que da forma a un discurso orientado a producir cambios históricos empíricos que lo trascienden, por lo que se enfatiza una orientación intracultural enfatizadora de la autonomía de un pueblo capaz de autodeterminarse y construir sus propios espacios políticos, sociales, culturales, educativos y organizativos, entre otros. En este sentido se observa un discurso que rebasa y excede las problemáticas estudiantiles universitarias y se inscribe en el marco de afianzamiento de la identidad mapuche en pos de la autonomía y autodeterminación como "Pueblo Nación Mapuche".

El dpm-eu se constituye así en un espacio discursivo en el cual interactúan conflictivamente los sujetos culturales; la sociedad mayoritaria es involucrada en el espacio textual mediante expresiones vocativas indirectas, por un lado, y, por otro, con la exposición de hechos que invocan sentimientos de reconocimiento, culpa y responsabilidad no asumidos por ésta, que textualmente no admite respuesta. En este sentido se trata de un discurso que no la apela significativamente $y$, en la medida en que lo hace 
carece del poder de demandar derechos o reivindicaciones. De esta etapa ya cursada insatisfactoriamente, se pasa a otra donde se hace presente a la sociedad global sus incumplimientos, maltratos y actitud discriminatoria con el pueblo mapuche y se le recuerda que la historia da cuenta de un pueblo autodeterminado. Al mismo tiempo, se pretende reanimar y reforzar a un pueblo que ya no pide a otros lo que es capaz de tener por sí mismo, y por eso los propósitos discursivos están ahora dirigidos a la propia sociedad, que es la responsable de luchar y lograr la autonomía como pueblo ${ }^{23}$.

Esta es la razón fundamental por la que el dpm-eu, nutriéndose de un discurso original necesariamente intercultural, en una forma apelativa directa, se orienta a la cultura propia con el propósito de recuperar la nación mapuche. Como se ha reiterado, en la instancia Apelación de la superestructura del discurso es donde mejor se evidencia esta orientación intracultural del discurso, como asimismo en la relevancia de la instancia destinataria mapuche, a la cual se entrega la responsabilidad actual y futura de asumir los problemas del pueblo mapuche como tal, procurándose la autodeterminación a través de la lucha sostenida y cada vez más comprometida con este propósito.

La relación comunicativa entre destinador y destinatario mapuches significa así la alianza en un propósito común de pueblo: "hacemos un llamado a nuestros hermanos mapuche de distintas organizaciones y sectores para aunar fuerzas y repudiar estos hechos que afectan de manera sistemática al conjunto de nuestra nación” (Decl. Pública, 17/04/2002, Hogar Universitario Mapuche).

En este contexto es necesario reconsiderar también la presencia permanente de la sociedad mayoritaria en el Protocolo de Apertura. Si la importancia "real" la tiene la cultura propia, a la cual se asigna la responsabilidad de recuperar las pérdidas ocasionadas por la cultura ajena, ¿qué sentido tiene la presencia de ésta en los discursos? Es claro que su presencia reviste significados que no la limitan a ser la responsable actual de restituir la identidad, autonomía, etc., aunque tampoco se la cree capaz de reparar el daño ocasionado de acuerdo a una interpretación de datos empíricos presentes y los argumentos históricos sólo cobran relevancia en la medida en que ayudan a revelar el origen del conflicto entre ambas sociedades y constituyen un testimonio de los hechos que sustentan el propósito de la lucha.

De esto se deriva también la tensión conflictual observada, pero más relevante es la complementariedad entre el carácter intracultural de la instancia comunicativa del discurso y la orientación intercultural del mismo; aquél nutre y sirve de base a los propósitos de éste. El carácter intercultural está en el origen del discurso debido a las relaciones conflictuadas con la cultura ajena y la orientación intracultural tiene que ver con los propósitos y funciones actuales orientados a la cultura propia.

Por esto es posible pensar en una complementariedad intercultural/intracultural del discurso de un grupo relativamente actual y moderno, sustentado en valores antiguos y tradicionales y al mismo tiempo en una mentalidad más cercana a la crítica y la autocrítica, como es la estudiantil universitaria. Esto permite pensar que una actitud de esta naturaleza abre proyecciones en el sentido de que esta relación intracultural/intercultural del discurso puede mantenerse en el tiempo y, en lugar de oponerse a la acción empírica social y cultural como ha ocurrido en gran medida hasta ahora, pueda proyectarse homológicamente en ella. De este modo, sobre la base del sentido del dpm hasta ahora, más cercano a la indigenidad que a la interculturalidad, es esperable que se avance en el diálogo necesario de estos sistemas categoriales en la existencia del pueblo mapuche en sus vinculaciones con la sociedad mayoritaria y, viceversa, hacia una mayor comprensión de esta última de la legítima indigenidad no opuesta a la inevitable y necesaria interculturalidad y a su mutuo acercamiento.

Como diría Jesús Martín Barbero, es necesario tener en cuenta una nueva concepción de los procesos de apropiación cultural que la inserción de las etnias en la modernidad neoliberal hace necesaria, para comprender sus modos de apropiarse de una economía y una cultura que les arremete, pero que no ha podido "suprimir ni reemplazar la peculiar mediación que esas culturas operan entre memoria y utopía (...) producción de una experiencia de encuentro y solidaridad en medio de la dispersión y la distancia impuestas por la ciudad" ajena (2002:139-140, el agregado es nuestro).

OBRAS CITADAS

Betancour, Sonia. 2005. "El discurso público mapuche estudiantil universitario". Tesis para optar al grado de Magíster en Ciencias de la Comunicación. Temuco, Facultad de Educación y Humanidades, Universidad de La Frontera.

—. 2004. "El discurso público mapuche estudiantil universitario". Lengua y Literatura Mapuche 11: 105-113. ${ }^{23}$ Si bien se destacan aquí estos rasgos por su énfasis en el dpm-eu, no debe olvidarse que ellos están igualmente presentes en el
dpm en general, como hemos observado en varias oportunidades, por ej., Carrasco 2004 . 
Temuco, Depto. de Lenguas, Literatura y Comunicación, Facultad Educación y Humanidades, Universidad de La Frontera.

Carrasco, Hugo. 1996. "El discurso público mapuche", Lengua y Literatura Mapuche 7: 105-107.

1998. "La lógica del discurso público mapuche", Lengua y Literatura Mapuche 8: 203-216.

2000. "Los tipos discursivos del discurso público mapuche", Lengua y Literatura Mapuche 9: 145-156.

2002. "El discurso público mapuche: complejo textual polisistémico producido para la prensa", Comunicación y Medios 13, año 13: 60-74.

— . 2002b. "El discurso público mapuche: noción, tipos discursivos e hibridez", Estudios Filológicos 37: 185197.

—. 2003. "Notas sobre la organización retórica del discurso público mapuche", Texto, Lingüística y Cultura. Comunicaciones seleccionadas XIV Congreso de la Sociedad Chilena de Lingüística. Osorno, SOCHIL-U. de Los Lagos.

—. 2004. "Retórica textual del discurso público mapuche", Lengua y Literatura Mapuche 11: 115-136.

—. 2005. "El discurso público mapuche: comunicación intercultural mediatizada", Estudios Filológicos 40: 4964.

Carrasco, Iván. 1979. "Dos discursos complementarios: las dedicatorias y las notas”, Estudios Filológicos 14: 129137.

Contreras, Verónica. 2000. "Los discursos verbales mapuches: El discurso público”, Revista $L$ y L (Nueva Epoca).

Ferry y Bolton. 1998. El nuevo espacio público. Barcelona: Gedisa.

Foerster, Rolf y Sonia Montecino. 1998. Organizaciones, líderes y contiendas mapuches: 1900-1970. Santiago: Ediciones CEM.

García, Mabel. 2000. "La autorrepresentación del emisor textual en el discurso público mapuche", Lengua y Literatura Mapuche 9: 177-190.

Iglesias, Montserrat. 1999. "La teoría de los polisistemas como desafío a los estudios literarios", Teoría de los Polisistemas. Dimic, Even-Zohar, Lambert et al. Madrid: Arco/Libros (Estudio y compilación de M. Iglesias) 9-20.

Imbert, Gerard. 1984. "Sujeto y espacio público en el discurso periodístico de la Transición. Hacia una Sociosemiótica de los discursos sociales", Teoría Semiótica. Lenguajes y Textos hispánicos de Miguel Angel Garrido. Madrid: C.S.I.C.E.

Martín Barbero, Jesús. 2002. Oficio de Cartógrafo. México: Fondo de Cultura Económica.

Otazo, Jaime. 2001. "Aspectos identitarios del actual discurso público mapuche”. [Ponencia, Universidad de Talca].

Rivadeneira, Raúl. 1990. Periodismo. La teoría general de sistemas y la ciencia de la comunicación. México: Editorial Trillas.

Schmidt. 1977. Teoría del Texto. Madrid: Cátedra.

Van Dijk, Teun. 1989. La ciencia del texto. Un enfoque interdisciplinario. Barcelona: Paidós.

Van Dijk, Teun. 1990. La noticia como discurso. Comprensión, estructura y producción de la información.

Barcelona: Paidós Comunicación. 